\title{
Role of Probiotic Bacilli in Developing Synbiotic Food: Challenges and Opportunities
}

\author{
Carolina Szlufman and Moshe Shemesh* \\ Department of Food Science, Institute of Postharvest Technology and Food Sciences, Agricultural Research Organization, \\ The Volcani Center, Rishon LeZion, Israel
}

The human body is inhabited by a vast diversity of probiotic microorganisms that could positively affect human physiology. Besides, prebiotic food substances may induce symbiotic relationship among probiotic species through the successful establishment of commensal microbiota, whose connections with the host are multifaceted and multidirectional. As deliberated throughout this review, prebiotic and synbiotic foods contain the capability to stimulate numerous health characteristics in host organisms through various means. Predominantly, the normal microbiota fosters the digestion of food and may boost the innate and adaptive immune system's functionalities. Therefore,

OPEN ACCESS

Edited by: Leon M. T. Dicks, Stellenbosch University, South Africa

Reviewed by:

Ahmed Gomaa, National Research Centre (Egypt),

Egypt

Md. Abul Kalam Azad, Institute of Subtropical Agriculture, Chinese Academy of Sciences, China

*Correspondence: Moshe Shemesh moshesh@agri.gov.il

Specialty section: This article was submitted to Microbiotechnology, a section of the journal Frontiers in Microbiology

Received: 07 December 2020 Accepted: 19 March 2021 Published: 12 April 2021

Citation: Szlufman $C$ and Shemesh $M$ (2021) Role of Probiotic Bacill in Developing Synbiotic Food: Challenges and Opportunities.

Front. Microbiol. 12:638830. doi: 10.3389/fmicb.2021.638830 live probiotic bacteria, for instance, probiotic Bacilli obtained together with prebiotic food, can help stimulate healthiness in humans. Thus, we discuss how certain dietary fibers may preserve the probiotic efficacy by serving as the scaffold for probiotic Bacilli to colonize them through forming symbiotic interactions. The fibers can essentially promote protection by encapsulating probiotic Bacilli against various environmental and physical stresses that might kill the free-living bacterial cells. Besides, these fibers would serve as prebiotic substances that would eventually be utilized for the proliferation of probiotic cells. It is believed that applying this conceptual idea will provide a novel platform toward developing probiotic and synbiotic foods, as discussed in this review.

Keywords: probiotics, Bacillus subtilis, LAB, beneficial biofilm, synbiotic food, probiotic Bacilli, dietary fibers, symbiotic encapsulation

\section{INTRODUCTION}

The human body is normally populated with an extensive assortment of microorganisms that may have a positive impact on human physiology and functions, such as the symbiotic relationship of probiotics along with prebiotics in the prevention of diseases (Hooper and Gordon, 2001; Lebeer et al., 2010; Davani-Davari et al., 2019). Historically, much before scientific research could examine the impacts of microbes on the internal human environment, many probiotic species were being used in dietary consumption for centuries. For example, they were used in the fermentation of dairy products, such as cheese and yogurt, as well as wine (Bokulich et al., 2015; Wolfe and Dutton, 2015). We now know that probiotics are live microorganisms, which reside in an organism and can contribute beneficially to the host' health (Lebeer et al., 2010; Fukuda et al., 2011; Piewngam et al., 2018). The probiotic supplements field is continuously growing since evidence suggests gut microbiota's essentiality in promoting body healthiness and well-being (Clemente et al., 2012; Wu and $\mathrm{Wu}, 2012$; Dhar and Mohanty, 2020). Therefore, possible manipulations of the microbiome 
composition in the gastrointestinal tract (GIT) of a host organism, specifically through consuming probiotic food, become a potential remedy.

The molecular interactions of the host with the microbiota are complex, numerous, and multidirectional. For instance, the microbiota of the human GIT exists in a crosstalk that ranges between mutualism and pathogenicity, fostered by residential and ingested microorganisms. The normal microbiota contributes to proper food digestion as well as the optimal functioning of the immune system (Hooper and Gordon, 2001). The gut microbiota is supposed to significantly regulate the development and function of the innate and adaptive immune system (Negi et al., 2019a). The gut microbiota and immune homeostasis seem to have a back and forth relationship and are a subject of intense research in the field of infectious diseases. Also, gut microbiota-derived signals regulate the immune cells for pro and anti-inflammatory responses, thereby affecting the susceptibility to various diseases (Negi et al., 2019b).

Interest in the microbiota's beneficial functions has resulted in the eventual selection of specific species with putative healthpromoting capacities. To exemplify, the Gram-positive Bacilli are prominent colonizers of the human GIT and thus have been widely used as probiotic species in clinical applications (Lebeer et al., 2010; Ilinskaya et al., 2017). Among the main benefits of those species are the positive interactions with the host organism by metabolizing various dietary components that may affect commensal microbiota composition as well as inducing defense mechanisms against infectious diseases (Figure 1). Specifically, probiotic Bacilli can metabolize different prebiotic compounds that promote the healthiness of the host organism in which they reside using different mechanisms; these mechanisms include: pathogen obstruction due to antagonism and competition, $\mathrm{pH}$ level preservation, and defense of intestinal mucosal barrier and its functions (Ilinskaya et al., 2017; Davani-Davari et al., 2019; Seifert et al., 2019). In addition, probiotic Bacilli have been related to the production of many health-promoting factors for the host organism, for instance, vitamins and small molecules such as aminobutyric acid (GABA; Gu et al., 2015; Wang et al., 2019; Ren et al., 2020); this four-carbon non-proteinogenic amino acid is well-known for its diverse biological functions such as anxiety inhibition, sleep promotion, blood pressure reduction, diabetes treatment, and immune enhancement (Li et al., 2016; Wang et al., 2019).

Among the most crucial mode of actions of probiotic Bacilli in mitigating pathogenic species, from either intestinal or respiratory tract, appears to be by modifying the microbiota composition within the GIT through creating a more favorable balance in the microbial population (Fukuda et al., 2011; Gagliardi et al., 2018; Li et al., 2019). The exclusion of pathogenic species often occurs by two major mechanisms: (i) through production of antimicrobial substances that may eliminate the undesired bacteria (Caulier et al., 2019; Kimelman and Shemesh, 2019) and (ii) by affecting gene expression patterns of pathogenic microorganisms resulting in the suppressed ability to colonize the GIT of the host organism (Piewngam et al., 2018). Besides, probiotic Bacilli may affect both innate and adaptive immunity through upholding intestinal homeostasis as well as improving different aspects of GIT functionality (Fukuda et al., 2011; Lefevre et al., 2015; Jager et al., 2018; Johnson et al., 2019). By improving the digestibility of nutrients, for instance, certain types of indigestible dietary fibers, could probiotic Bacilli vastly contribute to the host organism's healthiness (Rajasekharan et al., 2020). The pathogen eliminating, immunomodulatory and additional beneficial capabilities of probiotic Bacilli for the host organism, summarized in Table 1, paving the way for developing novel probiotic formulations as well as probiotic food for potential application in clinical dietetics as well as agriculture and food industry.

\section{CURRENT CHALLENGES TOWARD EFFECTIVE APPLICABILITY OF PROBIOTIC BACILLI}

Preserving the efficacy of probiotic Bacilli exhibits paramount challenges that need to be addressed toward developing functional and health-promoting products, such as probiotic and symbiotic foods (Cruz et al., 2012; Yahav et al., 2018; Terpou et al., 2019). It was recently postulated that there could be a pronounced improvement in health when probiotics are administered along with antibiotics (Li et al., 2018). Moreover, probiotic organisms can comprise a solution to antibiotic resistance in certain conditions. Yet, there is a challenge due to broad-spectrum antibiotics usage, which could be targeting the beneficial probiotic bacteria too. On the other hand, complex microbial comminutes called biofilms have been revealed to stimulate antibiotic resistance; therefore, the biofilms could protect probiotic cells against the administered antibiotics. Besides, probiotic Bacilli are capable for the removal of pathogenic species such as Staphylococcus aureus from the intestinal and respiratory tract (Piewngam et al., 2018). This finding opens new thinking and opportunities for developing novel antimicrobial strategies instead of using standard or topical antibiotics.

Another challenge in the field is that the known prebiotic substances that can alter the gut microbiota do not include a protein source. Given that proteins digested in the small intestine provide a nitrogen source for commensal species, it is very limited and competitive among colonic bacteria (Seifert et al., 2019). Since some proteins possess functional attributes that make them suitable for the encapsulation of bioactive agents (Fathi et al., 2018), they may provide an excellent delivery system for the nanoencapsulation of appropriate probiotic species. This approach would further facilitate the development of proteinbased symbiotic food.

\section{Dietary Fibers and Their Prebiotic Role}

Dietary fibers, defined as carbohydrate polymers (which are neither digested nor absorbed), are normally subjected to bacterial fermentation in the GIT (Holscher, 2017); thus, they may impact the composition of bacterial communities as well as microbial metabolic activities, including the production of different fermentative end products (Hamaker and Tuncil, 2014; Bindels et al., 2015). Some dietary fibers can also be classified as prebiotic substances referred to as "selectively fermented 


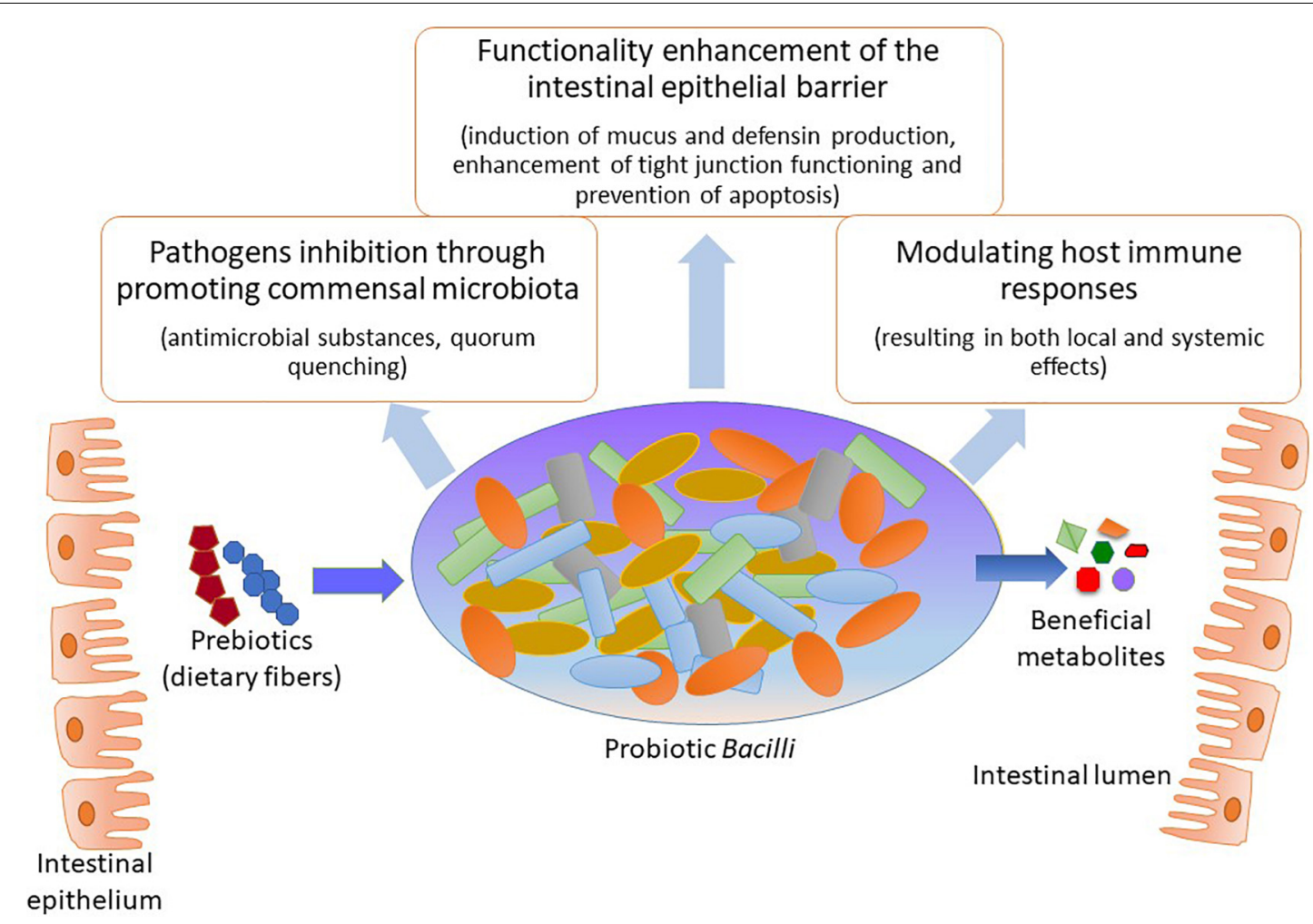

FIGURE 1 | Health promoting modes of action by probiotic Bacilli.

ingredients that result in specific changes, in the composition or activity of the gastrointestinal microbiota, thus conferring benefit(s) upon host health" (Slavin, 2013; Holscher, 2017).

Studies have shown that the consumption of fibers in the diet may account for a decrease in mortality, coronary heart disease, cancer, type 2 diabetes, gastrointestinal issues, and strokes (Anderson et al., 2009; Reynolds et al., 2019). Blood pressure and cholesterol can also be decreased as a result of increasing fiber intake. Moreover, consumption of the fibers may improve conditions associated with glycemia and insulin issues in non-diabetic and diabetic persons. Additionally, it can enhance weight loss in obese individuals (Anderson et al., 2009).

It appears that fibers are nearly entirely broken down by the active microflora in either small or large bowel, mainly through fermentation processes (Anderson et al., 2009; Holscher, 2017). Therefore, dietary fibers fermented by the gut microbiota through producing certain metabolic substances can shape the immunological environment in the host organism and influence the severity of allergic inflammation (Trompette et al., 2014). Moreover, the normal gut microbiota can resist adipose tissue formation due to fiber consumption by the probiotic bacteria (Delzenne et al., 2019). Thus, fibers may significantly contribute to establishing and maintaining healthy gut microbiota, which would help against pathogens, expansion of the gut immune system, and synthesize health promoting metabolites (Hamaker and Tuncil, 2014; Reynolds et al., 2019).

Apparently, probiotic Bacilli consumption can also enhance the normal functionality of the GIT by reducing the inflammation rate in humans (Rhayat et al., 2019). Besides, it was shown that a Lactobacillus reuteri could reduce the blood cholesterol level in mice through increasing a ratio of high to low density lipoprotein, which might indirectly account for the permanency of the lactobacilli in the gut (Taranto et al., 2000). Despite many evidences for beneficial functionalities of bacteria and fungi in the GIT that can play a significant role in positive cross-talk with the host organism (Wolfe et al., 2014; Bokulich et al., 2015; Wolfe and Dutton, 2015), they have not been fully categorized or characterized up until now.

\section{SYMBIOTIC ENCAPSULATION AS AN EFFECTIVE METHOD FOR DEVELOPING FUTURE PROBIOTICS}

It is conceivable that using prebiotics to encapsulate and transport probiotics would result in the simultaneous distribution of pre and probiotics into the colon (Seifert et al., 2019). Accordingly, innovative encapsulation techniques have been suggested for the food and probiotics industry to shield probiotic species from severe storage environments and gastrointestinal conditions (Li et al., 2018). Another efficient method for coating beneficial microbes has been recently reported using biointerfacial supramolecular self-assembly of lipid membranes (Cao et al., 2019). This method exhibited significantly improved survival of bacterial cells against 
TABLE 1 | Putative health-promoting modes of action by probiotic Bacilli.

\begin{tabular}{|c|c|c|c|}
\hline Mode of probiotic activity & Resulting functionality & Type of bacteria & References \\
\hline Modification of microbiota in the GIT & $\begin{array}{l}\text { Creating a more favorable microbial population } \\
\text { due to a shift in the balance toward beneficial } \\
\text { microorganisms }\end{array}$ & Various probiotic Bacilli & $\begin{array}{l}\text { Fukuda et al., 2011; } \\
\text { Gagliardi et al., 2018; } \\
\text { Vrancken et al., } 2019\end{array}$ \\
\hline $\begin{array}{l}\text { Alteration in gene expression of pathogenic } \\
\text { microorganisms by affecting quorum sensing }\end{array}$ & $\begin{array}{l}\text { Interfering signaling mechanisms in pathogenic } \\
\text { bacteria through influencing their pathogenicity } \\
\text { or survivability }\end{array}$ & B. subtilis & Piewngam et al., 2018 \\
\hline $\begin{array}{l}\text { Production of antimicrobial substances: } \\
\text { bacteriocins or lipopeptide compounds }\end{array}$ & $\begin{array}{l}\text { Growth inhibition of pathogenic microorganisms } \\
\text { in the intestine }\end{array}$ & $\begin{array}{l}\text { Typical to all probiotic } \\
\text { Bacilli }\end{array}$ & $\begin{array}{l}\text { Hong et al., 2005; } \\
\text { Caulier et al., } 2019\end{array}$ \\
\hline Spore-forming capability & $\begin{array}{l}\text { Remarkable ability to survive in harsh } \\
\text { environmental conditions }\end{array}$ & $\begin{array}{l}\text { Typical to all Bacillus } \\
\text { species }\end{array}$ & Hong et al., 2005 \\
\hline $\begin{array}{l}\text { Improving the digestibility of nutrients, mainly } \\
\text { due to enhanced enzyme activity in the } \\
\text { intestine, especially of } \alpha \text {-amylase, cellulase, } \\
\text { phytase, proteases, and metalloproteases }\end{array}$ & $\begin{array}{l}\text { Optimize mineral absorption, carbohydrate } \\
\text { digestion, reduction in cholesterol level, and } \\
\text { production of nutrients. }\end{array}$ & Bacillus coagulans & Jager et al., 2018 \\
\hline $\begin{array}{l}\text { Immunomodulation affecting both innate and } \\
\text { adaptive immunity }\end{array}$ & $\begin{array}{l}\text { Upholds intestinal homeostasis and improves } \\
\text { adaptive immune response }\end{array}$ & $\begin{array}{l}\text { Lactobacillus and } \\
\text { Bifidobacterium }\end{array}$ & $\begin{array}{l}\text { Fukuda et al., 2011; } \\
\text { Yan and Polk, } 2011\end{array}$ \\
\hline $\begin{array}{l}\text { Protecting probiotic cells via inducing biofilm } \\
\text { matrix production }\end{array}$ & $\begin{array}{l}\text { Sustain enzymes and offer safety against } \\
\text { osmotic stress, elevated temperatures, freeze } \\
\text { thawing, and drying processing protocols }\end{array}$ & $\begin{array}{l}\text { Different probiotic } \\
\text { Bacilli }\end{array}$ & $\begin{array}{l}\text { Yahav et al., 2018; } \\
\text { Terpou et al., } 2019\end{array}$ \\
\hline $\begin{array}{l}\text { Production of health-promoting factors for the } \\
\text { host organism, for instance, vitamins and small } \\
\text { molecules such as (GABA) }\end{array}$ & $\begin{array}{l}\text { Modulating diverse biological functions and } \\
\text { immune enhancement of host organism }\end{array}$ & $\begin{array}{l}\text { Different probiotic } \\
\text { Bacilli }\end{array}$ & $\begin{array}{l}\text { Li et al., 2016; Wang } \\
\text { et al., } 2019\end{array}$ \\
\hline Triggering anticariogenic activity & $\begin{array}{l}\text { Effective metabolism of sugar alcohols } \\
\text { reinforces the probiotic potential of Bacillus } \\
\text { spp. against pathogenic Streptococci }\end{array}$ & B. subtilis & $\begin{array}{l}\text { Duanis-Assaf et al., } \\
2020\end{array}$ \\
\hline Inducing antiviral activity & $\begin{array}{l}\text { modulating infectivity through either affecting } \\
\text { microbiota composition or production antiviral } \\
\text { substitutes }\end{array}$ & $\begin{array}{l}\text { Different probiotic } \\
\text { Bacilli }\end{array}$ & $\begin{array}{l}\text { Lefevre et al., 2015; } \\
\text { Johnson et al., } 2019\end{array}$ \\
\hline $\begin{array}{l}\text { Protecting against acute liver injury and } \\
\text { hyperammonemia }\end{array}$ & $\begin{array}{l}\text { Reducing inflammatory cell infiltration into the } \\
\text { liver and decreasing ammonia levels }\end{array}$ & L. salivarius & Yang et al., 2020 \\
\hline $\begin{array}{l}\text { Triggering anti-tumorogenic activity through } \\
\text { producing a probiotic bacteriocin }\end{array}$ & $\begin{array}{l}\text { Modulation of tumorogenic effect induced by } \\
\text { periodontal pathogens }\end{array}$ & $\begin{array}{l}\text { Different probiotic } \\
\text { Bacilli }\end{array}$ & Kamarajan et al., 2020 \\
\hline
\end{tabular}

environmental assaults during oral delivery and treatment using two murine models of colitis (Cao et al., 2019). Besides, it was also reported that the integration of different factors as abiotic as well as biotic should be taken into account during proper selection method for probiotic encapsulation for the specific system (Šipailienë and Petraitytë, 2018).

Additional bio-coating technique established lately may permit symbiotic advancement of biofilm-forming probiotic Bacilli with distinctive lactic acid bacteria (LAB; Kimelman and Shemesh, 2019). Besides, certain vitamins produced by probiotic Bacilli can promote cellular function if they survive harsh environmental barriers such as the colon and GIT. For example, LAB can synthesize folate, a B-group vitamin that humans cannot synthesize and must be exogenously obtained (Mosso et al., 2018). Therefore, increasing the folate content of tuber-based foods using LAB may provide novel food matrices to delivery probiotic microorganisms to humans (Mosso et al., 2018). Furthermore, probiotic Bacilli may facilitate the production of vitamin $B_{12}$ an essential water-soluble vitamin vital to prevent severe pathologies, some of which are irreversible (Molina et al., 2012).

Although the LAB are among the most prominent probiotic microorganisms (Yang et al., 2015; Yahav et al., 2018), they should be successfully established within the GIT system of the host organism to exert their beneficial effect. Consequently, it was recently proposed using the biofilm-inspired encapsulation of live probiotic cells through facilitating production of protecting extracellular matrix (Yahav et al., 2018; Kimelman and Shemesh, 2019) or by lipid-coated delivery system (Cao et al., 2019). Besides, induced production of different healthpromoting molecules, such as vitamins and neuroprotective substances, would facilitate the beneficial effects of the probiotic formulations (Figure 2). Therefore, it is believed that this conceptual idea will provide a basis for the development of a synbiotic food system facilitating the survivability of probiotic cells through inducing the production of health-promoting functional molecules.

\section{FUTURE PERSPECTIVES IN DEVELOPING EFFECTIVE SYNBIOTIC FOOD INCORPORATING THE PROBIOTIC BACILLI}

One of the potentially manageable foods for developing an effective synbiotic food system can be cereal grains, which offer the positive benefits of combining probiotic species 
with whole grains that may serve as a staple prebiotic substance. Recent studies indicate that certain probiotic microorganisms contain necessary components to be established as synbiotic food, for instance, cereal-based efficient products (Budhwar et al., 2020). Additionally, the usage of certain microorganisms as beginning cultures throughout the food fermentation process is a notably favorable technique to improve the taste and mineral bioavailability in native cerealbased fermented foods (Nkhata et al., 2018; Ogunremi et al., 2020). Fermented foods are superior in nutrients compared to their unfermented counterparts due to the activation of endogenous enzymes that degrade antinutritional factors.
Antioxidant properties of fermented foods are also elevated compared to their unfermented counterparts due to increased vitamin $\mathrm{C}$ and ease of release of different health-promoting bioactive compounds resulting from a weakening of grain matrix (Nkhata et al., 2018).

The preparation of cereals with advanced approaches creates an enhanced nutrient platform with a preferred amino acid pattern. Fermentation is considered an essential and accepted method, significantly decreasing the antinutrients existing in coarse cereals such as trypsin inhibitor, phytic acid, and tannins (Budhwar et al., 2020). Phytase activity is a beneficial technological characteristic in LAB proposed to be administered

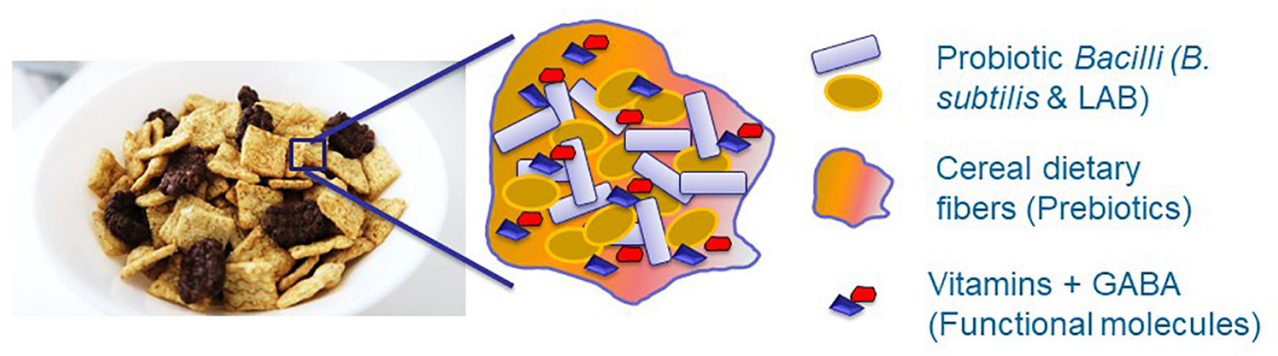

FIGURE 2 | The conceptual idea for developing synbiotic food system through facilitating survivability of probiotic cells and inducing production of health promoting functional molecules. Dietary fibers, for instance originated from cereals, can function as a scaffold for proliferation of probiotic species. Besides, these fibers can serve as a prebiotic substances for growth of probiotic bacteria as well as may facilitate production of health promoting molecules. Overall, it is believed that this symbiotic system will enhance survivability of probiotic bacteria against various environmental stresses.

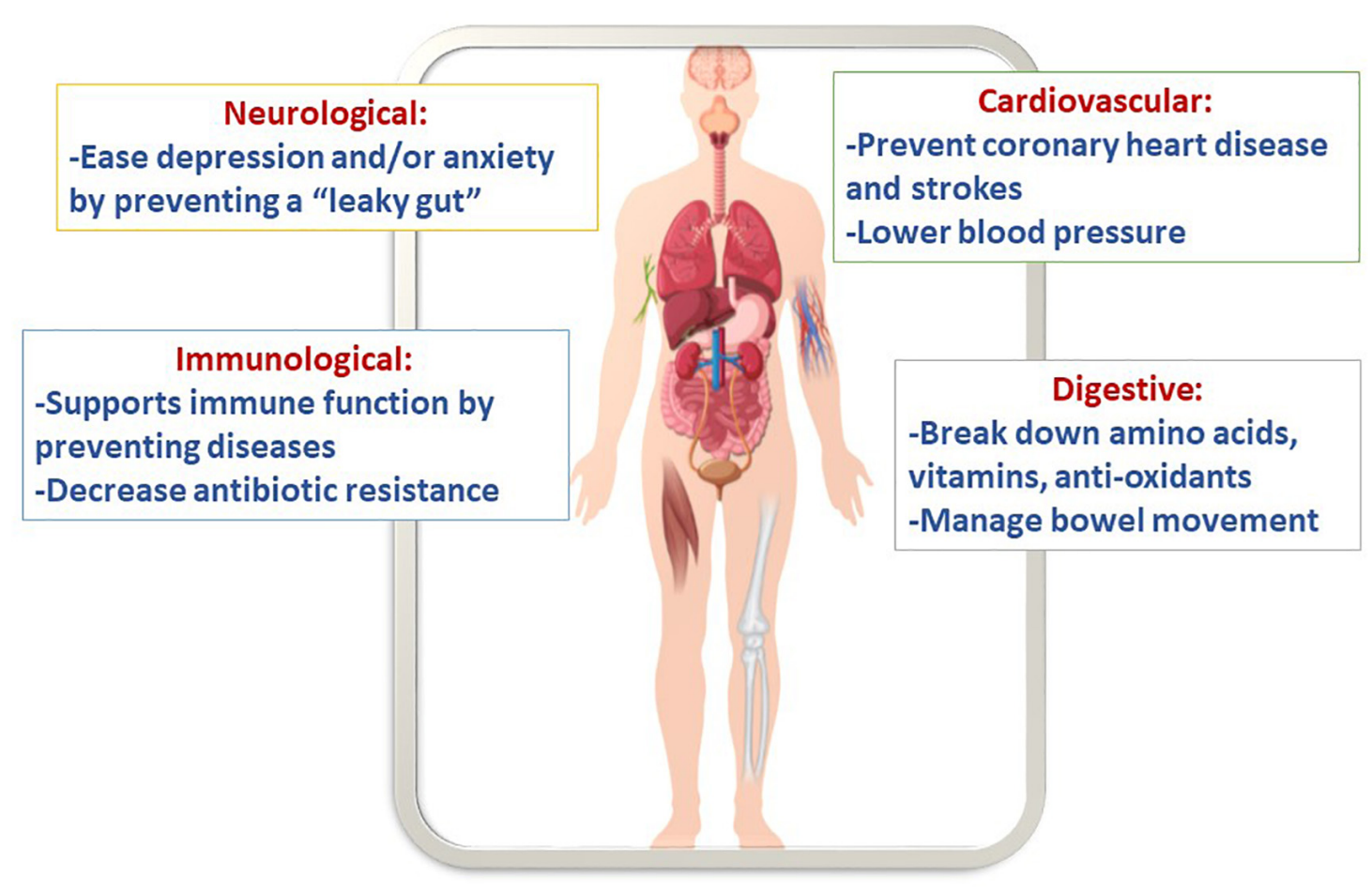

FIGURE 3 | Putative health benefits of synbiotic cereals. 
as starters in cereal and legume fermentations. Significant phytase activity in the presence of simulated gastrointestinal (SGI) fluids along with the ability to produce phytases post-exposure to the SGI fluids becomes of high interest (Amritha and Venkateswaran, 2018). Therefore, it augments the full nutritional value of coarse cereals and other food grains.

It is also apparent that different food matrices, for instance, dietary fibers of various food products, might serve as a natural scaffold for probiotic bacteria to adhere to and grow as biofilms. It was lately reported that the probiotic Bacilli could interact with resistant starch fibers of chickpea milk (CPM), along with the production of a reddish-pink pigment (Rajasekharan et al., 2020). Interestingly, the probiotic cells could use the resistant starch fibers as a scaffold and modify them to digestible fibers from another side (Rajasekharan et al., 2020). This finding may inspire the use CPM as a dietary supplement enriched with probiotics. CPM could serve as a natural source for prebiotics, the microbiome-shaping components that provide the carbon source for the beneficial microbes in the human gut. These fibers pass through the GIT virtually intact and undigested. In the lower GIT, they are utilized by gut microbiota, which digests them to distribute nutrients to the colonic epithelium, thus maintaining a functional and healthier digestive system (Rhayat et al., 2019). Enriching CPM with probiotics will generate a blend of the synbiotic complex, which might help the probiotic cells during transit through the acidic gastric environment without being killed (considering prebiotics might protect them and allow fast passage through the GIT).

Arguably, synbiotic cereals can promote health because gut microbiota demonstrated to imply a pronounced impact on numerous cellular and host functions (Figure 3). For example, these foods show an improvement in immunology, neurological functions, energy, storage, etc. Several bio-polymers can be hydrolyzed by probiotic bacteria into tiny metabolites that can be used right away. Some of these metabolites include amino acids, essential vitamins, and anti-oxidants, which are produced by the beneficial microbiota strains (Cukkemane et al., 2020). Additionally, it was reported that cereal grains consumption might prevent coronary disease and strokes (Anand et al., 2015). Moreover, probiotics are efficient in managing bowel movement and controlling pathogens such as Clostridium difficile, Campylobacter jejuni, and Helicobacter pylori (Roman et al., 2019). Since cereals are made of grains they contain a staple source of carbohydrate, dietary fiber, and protein. In addition, they are a suitable source of vitamins, such as the B-and E-groups of vitamins, and different vital minerals, such as iron, zinc, magnesium, and phosphorus. Moreover, phytochemicals, including phytoestrogens, antioxidants, and phenolics, are found in whole grain foods. When the phytochemicals are combined with vitamins and minerals, they could defend against gastrointestinal cancers and cardiovascular disease (Flight and Clifton, 2006).

Apparently, biofilm-forming probiotic Bacilli incorporated into the synbiotic cereals have a vast potential in survivability during the transition of acidic $\mathrm{pH}$ and subsequent establishment in the GIT. Moreover, the health-promoting activity of the cereals may further contribute to strengthening important immune responses to various infectious agents.

\section{CONCLUDING REMARKS}

As discussed throughout this communication, prebiotic and synbiotic foods can promote various health aspects in host organisms through different mechanisms. Primarily, the probiotic microbiota should promote the digestion of dietary fibers through enabling the proper functionality of the innate and adaptive immune system of the host organism.

Since Gram positive Bacilli are noticeable colonizers of the human GIT tract, they could be used as probiotic species in clinical practices to increase the body's defense mechanisms against infectious diseases. Predominantly, the normal microbiota contributes to food digestion and the development as well as the optimal functioning of the immune system. Therefore, the probiotic Bacilli obtained with food can be beneficial in stimulating a healthiness in human through obtaining bacterial viability in the acidic conditions of the stomach and the high bile concentration in the small intestine. Thus, recently developed biofilm-inspired encapsulation systems may protect probiotic Bacilli using food matrices such as dietary fibers. We discussed how certain dietary fibers might serve as the scaffold for the probiotic Bacilli to colonize them through forming multicellular communities. The fibers can essentially promote protection by encapsulating probiotic bacteria against various environmental and physical stresses that might kill the free-living bacterial cells. Besides, these fibers would serve as a prebiotic substance that would eventually be utilized by the probiotic cells. Therefore, it is feasible to apply this novel platform for various applications, for instance, probiotic and synbiotic food: snacks, candies, and cereals. Additionally, the synbiotic food harboring probiotic species can antagonize pathogenic bacteria, involved in different diseases from dental caries to irritated bowel syndrome.

\section{AUTHOR CONTRIBUTIONS}

Both authors developed a conceptual idea, originated the draft, prepared the illustrations for the manuscript, discussed and elaborated on the role of probiotic Bacilli in human health, and approved the final version of the manuscript.

\section{FUNDING}

This work was partially supported by the Chief Scientist of The Ministry of Agriculture (Israel).

\section{ACKNOWLEDGMENTS}

We are grateful to Onward Israel for enabling CS to participate in the Onward Israel Remote 2020 Internship Program in collaboration with Agricultural Research Organization of Israel. 


\section{REFERENCES}

Amritha, G. K., and Venkateswaran, G. (2018). Use of Lactobacilli in cereal-legume fermentation and as potential probiotics towards phytate hydrolysis. Probiotics Antimicrob. Proteins 10, 647-653. doi: 10.1007/s12602-017-9328-0

Anand, S. S., Hawkes, C., de Souza, R. J., Mente, A., Dehghan, M., Nugent, R., et al. (2015). Food consumption and its impact on cardiovascular disease: importance of solutions focused on the globalized food system: a report from the workshop convened by the world heart federation. J. Am. Coll. Cardiol. 66, 1590-1614. doi: 10.1016/j.jacc.2015.07.050

Anderson, J. W., Baird, P., Davis, R. H., Ferreri, S., Knudtson, M., Koraym, A., et al. (2009). Health benefits of dietary fiber. Nutr. Rev. 67, 188-205.

Bindels, L. B., Delzenne, N. M., Cani, P. D., and Walter, J. (2015). Towards a more comprehensive concept for prebiotics. Nat. Rev. Gastroenterol. Hepatol. 12, 303-310. doi: 10.1038/nrgastro.2015.47

Bokulich, N. A., Amiranashvili, L., Chitchyan, K., Ghazanchyan, N., Darbinyan, K., Gagelidze, N., et al. (2015). Microbial biogeography of the transnational fermented milk matsoni. Food Microbiol. 50, 12-19. doi: 10.1016/j.fm.2015.01. 018

Budhwar, S., Sethi, K., and Chakraborty, M. (2020). Efficacy of germination and probiotic fermentation on underutilized cereal and millet grains. Food Prod. Process. Nutr. 2:12.

Cao, Z., Wang, X., Pang, Y., Cheng, S., and Liu, J. (2019). Biointerfacial selfassembly generates lipid membrane coated bacteria for enhanced oral delivery and treatment. Nat. Commun. 10:5783.

Caulier, S., Nannan, C., Gillis, A., Licciardi, F., Bragard, C., and Mahillon, J. (2019). Overview of the antimicrobial compounds produced by members of the Bacillus subtilis group. Front. Microbiol. 10:302. doi: 10.3389/fmicb.2019.00302

Clemente, J. C., Ursell, L. K., Parfrey, L. W., and Knight, R. (2012). The Impact of the gut microbiota on human health: an integrative view. Cell 148, 1258-1270. doi: 10.1016/j.cell.2012.01.035

Cruz, A. G., Castro, W. F., Faria, J. A., Lollo, P. C., Amaya-Farfan, J., Freitas, M. Q., et al. (2012). Probiotic yogurts manufactured with increased glucose oxidase levels: postacidification, proteolytic patterns, survival of probiotic microorganisms, production of organic acid and aroma compounds. J. Dairy Sci. 95, 2261-2269. doi: 10.3168/jds.2011-4582

Cukkemane, A., Kumar, P., and Sathyamoorthy, B. (2020). A metabolomics footprint approach to understanding the benefits of synbiotics in functional foods and dietary therapeutics for health, communicable and non-communicable diseases. Food Res. Int. 128:108679. doi: 10.1016/j.foodres.2019.108679

Davani-Davari, D., Negahdaripour, M., Karimzadeh, I., Seifan, M., Mohkam, M., Masoumi, S. J., et al. (2019). Prebiotics: definition, types, sources, mechanisms, and clinical applications. Foods 8:92. doi: 10.3390/foods8030092

Delzenne, N. M., and Bindels, L. B. (2019). Food for thought about manipulating gut bacteria. Nature 577, 32-34. doi: 10.1038/d41586-019-03704-z

Dhar, D., and Mohanty, A. (2020). Gut microbiota and Covid-19-possible link and implications. Virus Res. 285:198018. doi: 10.1016/j.virusres.2020.198018

Duanis-Assaf, D., Steinberg, D., and Shemesh, M. (2020). Efficiency of Bacillus subtilis metabolism of sugar alcohols governs its probiotic effect against cariogenic Streptococcus mutans. Artif. Cells Nanomed. Biotechnol. 48, 12221230. doi: 10.1080/21691401.2020.1822855

Fathi, M., Donsi, F., and McClements, D. J. (2018). Protein-based delivery systems for the nanoencapsulation of food ingredients. Compr. Rev. Food Sci. Food Saf. 17, 920-936. doi: 10.1111/1541-4337.12360

Flight, I., and Clifton, P. (2006). Cereal grains and legumes in the prevention of coronary heart disease and stroke: a review of the literature. Eur. J. Clin. Nutr. 60, 1145-1159. doi: 10.1038/sj.ejcn.1602435

Fukuda, S., Toh, H., Hase, K., Oshima, K., Nakanishi, Y., Yoshimura, K., et al. (2011). Bifidobacteria can protect from enteropathogenic infection through production of acetate. Nature 469, 543-547. doi: 10.1038/nature09646

Gagliardi, A., Totino, V., Cacciotti, F., Iebba, V., Neroni, B., Bonfiglio, G., et al. (2018). Rebuilding the gut microbiota ecosystem. Int. J. Environ. Res. Public Health 15:1679. doi: 10.3390/ijerph15081679

Gu, Q., Zhang, C., Song, D., Li, P., and Zhu, X. (2015). Enhancing vitamin B12 content in soy-yogurt by Lactobacillus reuteri. Int. J. Food Microbiol. 206, 56-59. doi: 10.1016/j.ijfoodmicro.2015.04.033
Hamaker, B. R., and Tuncil, Y. E. (2014). A Perspective on the complexity of dietary fiber structures and their potential effect on the gut microbiota. J. Mol. Biol. 426, 3838-3850. doi: 10.1016/j.jmb.2014.07.028

Holscher, H. D. (2017). Dietary fiber and prebiotics and the gastrointestinal microbiota. Gut Microbes 8, 172-184. doi: 10.1080/19490976.2017.1290756

Hong, H. A., Duc, L. H., and Cutting, S. M. (2005). The use of bacterial spore formers as probiotics. FEMS Microbiol. Rev. 29, 813-835. doi: 10.1016/j.femsre. 2004.12.001

Hooper, L. V., and Gordon, J. I. (2001). Commensal host-bacterial relationships in the gut. Science 292, 1115-1118. doi: 10.1126/science.1058709

Ilinskaya, O. N., Ulyanova, V. V., Yarullina, D. R., and Gataullin, I. G. (2017). Secretome of Intestinal Bacilli: a natural guard against pathologies. Front. Microbiol. 8:1666. doi: 10.3389/fmicb.2017.01666

Jager, R., Purpura, M., Farmer, S., Cash, H. A., and Keller, D. (2018). Probiotic Bacillus coagulans GBI-30, 6086 improves protein absorption and utilization. Probiotics Antimicrob. Proteins 10, 611-615. doi: 10.1007/s12602-017-9354-y

Johnson, B. A., Hage, A., Kalveram, B., Mears, M., Plante, J. A., Rodriguez, S. E., et al. (2019). Peptidoglycan-Associated Cyclic Lipopeptide Disrupts Viral Infectivity. J. Virol. 93, e1282-e1219.

Kamarajan, P., Ateia, I., Shin, J. M., Fenno, J. C., Le, C., Zhan, L., et al. (2020). Periodontal pathogens promote cancer aggressivity via TLR/MyD88 triggered activation of Integrin/FAK signaling that is therapeutically reversible by a probiotic bacteriocin. PLoS Pathog. 16:e1008881. doi: 10.1371/journal.ppat. 1008881

Kimelman, H., and Shemesh, M. (2019). Probiotic bifunctionality of Bacillus subtilis-rescuing lactic acid bacteria from desiccation and antagonizing pathogenic Staphylococcus aureus. Microorganisms 7:407. doi: 10.3390/ microorganisms 7100407

Lebeer, S., Vanderleyden, J., and De Keersmaecker, S. C. J. (2010). Host interactions of probiotic bacterial surface molecules: comparison with commensals and pathogens. Nat. Rev. Microbiol. 8, 171-184. doi: 10.1038/nrmicro2297

Lefevre, M., Racedo, S. M., Ripert, G., Housez, B., Cazaubiel, M., Maudet, C., et al. (2015). Probiotic strain Bacillus subtilis CU1 stimulates immune system of elderly during common infectious disease period: a randomized, double-blind placebo-controlled study. Immun. Ageing 12:24.

Li, K. L., Wang, B. Z., Li, Z. P., Li, Y. L., and Liang, J. J. (2019). Alterations of intestinal flora and the effects of probiotics in children with recurrent respiratory tract infection. World J .Pediatr. 15, 255-261. doi: 10.1007/s12519019-00248-0

Li, W., Wei, M., Wu, J., Rui, X., and Dong, M. (2016). Novel fermented chickpea milk with enhanced level of gamma-aminobutyric acid and neuroprotective effect on PC12 cells. PeerJ. 4:e2292. doi: 10.7717/peerj.2292

Li, Z. H., Behrens, A. M., Ginat, N., Tzeng, S. Y., Lu, X. G., Sivan, S., et al. (2018). Biofilm-inspired encapsulation of probiotics for the treatment of complex infections. Adv. Mater. 30:e1803925.

Molina, V., Médici, M., Font de Valdez, G., and Taranto, M. P. (2012). Soybeanbased functional food with vitamin B12-producing lactic acid bacteria. J. Funct. Foods 4, 831-836. doi: 10.1016/j.jff.2012.05.011

Mosso, A. L., Jimenez, M. E., Vignolo, G., LeBlanc, J. G., and Samman, N. C. (2018). Increasing the folate content of tuber based foods using potentially probiotic lactic acid bacteria. Food Res. Int. 109, 168-174. doi: 10.1016/j.foodres.2018.03. 073

Negi, S., Das, D. K., Pahari, S., Nadeem, S., and Agrewala, J. N. (2019a). Potential role of gut microbiota in induction and regulation of innate immune memory. Front. Immunol. 10:2441. doi: 10.3389/fimmu.2019.02441

Negi, S., Pahari, S., Bashir, H., and Agrewala, J. N. (2019b). Gut microbiota regulates mincle mediated activation of lung dendritic cells to protect against Mycobacterium tuberculosis. Front. Immunol. 10:1142. doi: 10.3389/fimmu. 2019.01142

Nkhata, S. G., Ayua, E., Kamau, E. H., and Shingiro, J. B. (2018). Fermentation and germination improve nutritional value of cereals and legumes through activation of endogenous enzymes. Food Sci. Nutr. 6, 2446-2458. doi: 10.1002/ fsn3.846

Ogunremi, O. R., Agrawal, R., and Sanni, A. (2020). Production and characterization of volatile compounds and phytase from potentially probiotic yeasts isolated from traditional fermented cereal foods in Nigeria. J. Genet. Eng. Biotechnol. 18:16. 
Piewngam, P., Zheng, Y., Nguyen, T. H., Dickey, S. W., Joo, H. S., Villaruz, A. E., et al. (2018). Pathogen elimination by probiotic Bacillus via signalling interference. Nature 562, 532-537. doi: 10.1038/s41586-018-0616-y

Rajasekharan, S. K., Paz-Aviram, T., Galili, S., Berkovich, Z., Reifen, R., and Shemesh, M. (2020). Biofilm formation onto starch fibres by Bacillus subtilis governs its successful adaptation to chickpea milk. Microb. Biotechnol. 0, 1-8. doi: 10.1111/1751-7915.13665

Ren, L. J., Peng, C., Hu, X. C., Han, Y. W., and Huang, H. (2020). Microbial production of vitamin K2: current status and future prospects. Biotechnol. Adv. 39:107453. doi: 10.1016/j.biotechadv.2019.107453

Reynolds, A., Mann, J., Cummings, J., Winter, N., Mete, E., and Te Morenga, L. (2019). Carbohydrate quality and human health: a series of systematic reviews and meta-analyses. Lancet 393, 434-445. doi: 10.1016/s0140-6736(18)31809-9

Rhayat, L., Maresca, M., Nicoletti, C., Perrier, J., Brinch, K. S., Christian, S., et al. (2019). Effect of Bacillus subtilis strains on intestinal barrier function and inflammatory response. Front. Immunol. 10:564. doi: 10.3389/fimmu.2019. 00564

Roman, G. C., Jackson, R. E., Gadhia, R., Roman, A. N., and Reis, J. (2019). Mediterranean diet: the role of long-chain omega-3 fatty acids in fish; polyphenols in fruits, vegetables, cereals, coffee, tea, cacao and wine; probiotics and vitamins in prevention of stroke, age-related cognitive decline, and Alzheimer disease. Rev Neurol. 175, 724-741.

Seifert, A., Kashi, Y., and Livney, Y. D. (2019). Delivery to the gut microbiota: a rapidly proliferating research field. Adv. Colloid Interface Sci. 274:102038. doi: $10.1016 /$ j.cis.2019.102038

Šipailienë, A., and Petraitytë, S. (2018). Encapsulation of probiotics: proper selection of the probiotic strain and the influence of encapsulation technology and materials on the viability of encapsulated microorganisms. Probiotics Antimicrob. Proteins 10, 1-10. doi: 10.1007/s12602-017-9347-x

Slavin, J. (2013). Fiber and prebiotics: mechanisms and health benefits. Nutrients 5 , 1417-1435. doi: 10.3390/nu5041417

Taranto, M. P., Medici, M., Perdigon, G., Holgado, A. P. R., and Valdez, G. F. (2000). Effect of Lactobacillus reuteri on the prevention of hypercholesterolemia in mice. J. Dairy Sci. 83, 401-403. doi: 10.3168/jds.s0022-0302(00)74895-8

Terpou, A., Papadaki, A., Lappa, I. K., Kachrimanidou, V., Bosnea, L. A., and Kopsahelis, N. (2019). Probiotics in food systems: significance and emerging strategies towards improved viability and delivery of enhanced beneficial value. Nutrients 11:1591. doi: 10.3390/nu11071591

Trompette, A., Gollwitzer, E. S., Yadava, K., Sichelstiel, A. K., Sprenger, N., NgomBru, C., et al. (2014). Gut microbiota metabolism of dietary fiber influences allergic airway disease and hematopoiesis. Nat. Med. 20, 159-166. doi: 10.1038/ nm.3444

Vrancken, G., Gregory, A. C., Huys, G. R. B., Faust, K., and Raes, J. (2019). Synthetic ecology of the human gut microbiota. Nat. Rev. Microbiol. 17, 754763. doi: 10.1038/s41579-019-0264-8

Wang, H., Huang, J., Sun, L., Xu, F., Zhang, W., and Zhan, J. (2019). An efficient process for co-production of gamma-aminobutyric acid and probiotic Bacillus subtilis cells. Food Sci. Biotechnol. 28, 155-163. doi: 10.1007/s10068-0180461-7

Wolfe, B. E., and Dutton, R. J. (2015). Fermented foods as experimentally tractable microbial ecosystems. Cell 161, 49-55. doi: 10.1016/j.cell.2015.02.034

Wolfe, B. E., Button, J. E., Santarelli, M., and Dutton, R. J. (2014). Cheese rind communities provide tractable systems for in situ and in vitro studies of microbial diversity. Cell 158, 422-433. doi: 10.1016/j.cell.2014.05.041

$\mathrm{Wu}, \mathrm{H}$. J., and Wu, E. (2012). The role of gut microbiota in immune homeostasis and autoimmunity. Gut Microbes 3, 4-14. doi: 10.4161/gmic.19320

Yahav, S., Berkovich, Z., Ostrov, I., Reifen, R., and Shemesh, M. (2018). Encapsulation of beneficial probiotic bacteria in extracellular matrix from biofilm-forming Bacillus subtilis. Artif. Cells Nanomed. Biotechnol. 46, 974-982. doi: 10.1080/21691401.2018.1476373

Yan, F., and Polk, D. B. (2011). Probiotics and immune health. Curr. Opin. Gastroenterol. 27, 496-501. doi: 10.1097/MOG.0b013e32834baa4d

Yang, L., Bian, X., Wu, W., Lv, L., Li, Y., Ye, J., et al. (2020). Protective effect of Lactobacillus salivarius Li01 on thioacetamide-induced acute liver injury and hyperammonaemia. Microb. Biotechnol. 13, 1860-1876. doi: 10.1111/17517915.13629

Yang, P., Wang, J., and Qi, Q. (2015). Prophage recombinases-mediated genome engineering in Lactobacillus plantarum. Microb. Cell Fact $14: 154$.

Conflict of Interest: The authors declare that the research was conducted in the absence of any commercial or financial relationships that could be construed as a potential conflict of interest.

Copyright (c) 2021 Szlufman and Shemesh. This is an open-access article distributed under the terms of the Creative Commons Attribution License (CC BY). The use, distribution or reproduction in other forums is permitted, provided the original author(s) and the copyright owner(s) are credited and that the original publication in this journal is cited, in accordance with accepted academic practice. No use, distribution or reproduction is permitted which does not comply with these terms. 